\title{
Enhancing quality of vocational training outcome to satisfy the labor market demands in Kuwait by using Quality Function Deployment method (QFD)
}

\author{
Riyadh Mohammed Ali Hamza \\ Gulf University (BAHRAIN) \\ dr.rijadh@gulfuniversity.net
}

Received August 2010

Accepted January 2011

\section{Abstract:}

Purpose: The purpose of this paper is to develop a system to enhance the quality of vocational training programs in Kuwait state by using the concept of Quality Function Deployment (QFD).

Approach: The approach starts by investigating the private sector of the labor market. The interviewing of a sample group of the private sector companies was done to know their expectation of the performance of vocational training outcomes. Then, QFD was applied to find the technical requirements, which will help in satisfying the market's expectations to design a new program that leads to enhancement of the quality of the outcome of the Vocational Training. The house of quality technique allows prioritizing the technical descriptors based on the technical difficulty, target value, absolute weight, and relative weight.

Findings: The first priority that found from applying the QFD is the parameter "Practice to Be Willing in Learning- Applying New Technologies" because of its highest relative weight 195 points followed by the parameter "Understanding The Need to Learn New Skills" which has a relative weight of 165 points. The second priority is the parameter "Simulation Activities" because it has a relative weight of 152 points followed by the parameter "Managing Tasks and Meeting Deadlines" 
which has a relative weight of 146 points. The third priority is the parameter "Using IT Skills to Complete Activities" because of it has a relative weight is 132 points followed by the parameter "Time Management Activities" which has a relative weight is 112 points.

Research limitation: The research limitation is in the changing of the current curriculum program.

Practical implications: The practical implication is to modify the students' vocational training curriculum, by adapting new technologies and application sequences of activities and solution strategies within the time limit.

Value: The value of this paper is to explain how a studying curriculum can be modified in order to satisfy the market requirements.

Keywords: quality function deployment, QFD, voice of customer, VOC, vocational training outcomes, labor market demand

\section{Introduction}

This paper provides a scheme to enhance the quality of vocational training outcome to satisfy the labor market demands in Kuwait State by using Quality Function Deployment (QFD) Method for program development. Noonan and et al. (2007) highlights the twenty-first century workforce requirements in light of three new challenges: (1) the need for an increase in the quality and quantity of skilled workers; (2) the need for employees who are lifelong learners and have transferable skills; and (3) the need for flexible, adaptable career technical education systems.

Hoeckel and Field (2008) define the Vocational Training as preparing the learners for jobs that are based in manual or practical activities, traditionally nonacademic and totally related to a specific trade, occupation or vocation, hence the term, in which the learner participates. It is sometimes referred to as technical education, as the learner directly develops expertise in a particular group of techniques or 
technology. Seyfried (1998) Study shows that Vocational Training organizations began movements for the assurance of quality in vocational training from the beginning of the 1990s in Europe. Sector Skill Development Agency (SSDA) (2007) defines Occupational Standards of performance that people are expected to achieve in their work and the knowledge and skills they need to perform effectively. Occupational Standards set out measurable performance outcomes to which an individual is expected to work in a given occupation. This paper is to develop a system to enhance the quality of vocational training programs in Kuwait state by using the concept of Quality Function Deployment (QFD).

\section{Quality Function Deployment review}

Maguad (2009) shows Quality Function Deployment (QFD) emphasizes the concept of Voice Of Customer (VOC) as a guide line to improve the products and services provided. The needs of their customers the first time and every time, QFD advocates listening to customers first. It assists the translation of customers' requirements all the way back in any business process that the end product or service actually satisfies those demands. Mazur (1994) explains Quality Function Deployment has been successfully recorded in the field of education in the United States. The first application of QFD in education took place in 1991; When the Mechanical Engineering Department of the University of Wisconsin Madison used QFD to obtain students' feedback on the Mechanical engineering undergraduate curriculum and to help change the curriculum. Research by Franceschini and Terzago (1998) showed the application QFD to industrial training courses. It identifies the differences between the application of QFD for product development and the education use. A study done by Gonzalez, Quesada, Gourdin and Hartley (2008) showed designing a supply chain management academic curriculum using QFD. The study concludes that the application of QFD and benchmarking as a joint analysis tool is a very interesting approach because the information is analyzed from different perspectives simultaneously. Succeeding of QFD in the field of education and improving quality in services gives an encouragement to proceed to apply QFD on vocational training field in Kuwait. That leads to enhance the quality of the outcome of vocational training by verifying the specifications, prioritizing skills demanded by the private labor market, and to deploy those demanded skills in the training programs. 


\section{The methodology}

\subsection{Overview of the outcome of the vocational training in Kuwait}

The first step is to have a solid feedback and a measure to know the present status of the labor market. How many of the local vocational training outcomes are there in the private sector of the labor market? What is the percentage of that outcome among the total workers of the market? Manpower Government Reconstructing Program (MGRP) record shows (see table 1) a record of the percentage of the vocational Kuwaiti outcomes in local market demand of private sector in Kuwait State. The next step is to scan the market to evaluate how strong the reception of the private sector of the labor market on the outcomes of the local vocational training. These steps and others can be achieved by the following:

\section{Surveys and questionnaires}

Hamza and Alrowaih (2010) made Surveys and Questionnaires. The questionnaires were distributed to the graduated students of the past three years. The first questionnaire was distributed to 40 graduated students for the period (2006-2009) from public vocational training authority in Kuwait. These surveys and questionnaires concentrate on the following aspects:

1. The waiting time to be accepted to work for a company.

2. The missing skills needed to be competed at the workplace.

3. Number of companies refuses the graduate employment application.

4. Reasons of refusal.

5. The relation between the current job and the subject trained for.

\section{$\underline{\text { Interviews }}$}

Interviews have been made with the Vocational Center's Alumnae Relation Offices to check their database for information required. An analysis study was done on the collected data that clarified the level of difficulties that graduate students' faces before entering the labor market. 
Set of surveys and interviews

Set of surveys and interviews also were distributed among the private labor market companies to evaluate the productivity of the workers from the vocational training providers in Kuwait State.

\begin{tabular}{|c|c|c|c|c|c|}
\hline \multirow{3}{*}{ Occupations } & \multicolumn{4}{|c|}{ Percentage } & \multirow{3}{*}{ Total } \\
\hline & \multicolumn{2}{|c|}{ KW Voc. Outcome } & \multicolumn{2}{|c|}{$\begin{array}{l}\text { Other } \\
\text { Source Outcome }\end{array}$} & \\
\hline & Count & $\%$ & Count & $\%$ & \\
\hline Technician & 94 & $1.1 \%$ & 8127 & $98.9 \%$ & 8221 \\
\hline Carpenter & 0 & $0 \%$ & 4426 & $100.0 \%$ & 4426 \\
\hline Electrician & 27 & $.6 \%$ & 4165 & $99.4 \%$ & 4192 \\
\hline Metal Technician & 0 & $0 \%$ & 3098 & $100.0 \%$ & 3098 \\
\hline Mechanics & 40 & $2.0 \%$ & 1971 & $98.0 \%$ & 2011 \\
\hline Constructional Vehicle Operators & 0 & $0 \%$ & 1704 & $100.0 \%$ & 1704 \\
\hline Painter & 0 & $0 \%$ & 1540 & $100.0 \%$ & 1540 \\
\hline Welder & 4 & $.3 \%$ & 1498 & $99.7 \%$ & 1502 \\
\hline A/C Technician & 3 & $.2 \%$ & 1433 & $99.8 \%$ & 1436 \\
\hline Accountant & 14 & $1.0 \%$ & 1375 & $99.0 \%$ & 1389 \\
\hline Concrete Frame work & 0 & $0 \%$ & 1236 & $100.0 \%$ & 1236 \\
\hline Technician Assistant & 30 & $3.0 \%$ & 973 & $97.0 \%$ & 1003 \\
\hline Supervisor & 109 & $13.0 \%$ & 728 & $87.0 \%$ & 837 \\
\hline Mechanic & 20 & $2.7 \%$ & 715 & $97.3 \%$ & 735 \\
\hline Plumber & 2 & $.3 \%$ & 696 & $99.7 \%$ & 698 \\
\hline Decoration & 0 & $0 \%$ & 634 & $100.0 \%$ & 634 \\
\hline Super Attendance & 10 & $1.6 \%$ & 600 & $98.4 \%$ & 610 \\
\hline Mechanic assistance & 2 & $.3 \%$ & 572 & $99.7 \%$ & 574 \\
\hline Inventory & 8 & $1.5 \%$ & 532 & $98.5 \%$ & 540 \\
\hline Arc Welder & 0 & $0 \%$ & 495 & $100.0 \%$ & 495 \\
\hline Maintenance & 16 & $5.9 \%$ & 256 & $94.1 \%$ & 272 \\
\hline Electrical Assistances & 2 & $.7 \%$ & 265 & $99.3 \%$ & 267 \\
\hline Equipment Operator & 1 & $.4 \%$ & 264 & $99.6 \%$ & 265 \\
\hline Sale Representative & 13 & $5.0 \%$ & 249 & $95.0 \%$ & 262 \\
\hline Engineering Drawing & 2 & $.8 \%$ & 257 & $99.2 \%$ & 259 \\
\hline Gas Welding & 0 & $0 \%$ & 258 & $100.0 \%$ & 258 \\
\hline Project Manager & 5 & $2.1 \%$ & 235 & $97.9 \%$ & 240 \\
\hline Drafter & 0 & $0 \%$ & 225 & $100.0 \%$ & 225 \\
\hline Computer Programmer & 4 & $1.8 \%$ & 217 & $98.2 \%$ & 221 \\
\hline Receptionist & 71 & $37.8 \%$ & 117 & $62.2 \%$ & 188 \\
\hline Total & 694 & & 44695 & & 45389 \\
\hline
\end{tabular}

Table 1. "Percentage of the vocational outcomes in the private sector in Kuwait state".

Source: Manpower Government Reconstructing Program (MGRP) record, State of Kuwait.

\subsection{Requirements and skills needed by the private labor market}

Sets of surveys were designed and distributed into the labor market covering the main three size categories of companies. Large companies those have more than 250 employees, middle size companies those have less than 200 employees and small size companies which have less than 50 employees. The study covers the services sector, industrial sector, constructional sector, as well as technology 
sectors. The focus on this stage is to get direct answers to specify skills required from vocational training providers. The survey was assessed using a 5-point Likert scale $(5 p t=$ Very important, $4 p t s=$ important, 3 pts Average, 2 pts not important, 1 pts sure not important) and includes 50 companies, nearly 40 skills were specified and then it were reduced to Top Ten Important skills (TIS) based on the highest important ten scores means of the answers.

\section{Results and discussions}

\subsection{Market analysis and survey results}

The survey questionnaires for the labor market demand shows the top ten important skills of most demanded, which were verified and inserted into the HOQ matrix. The calculation parameters prioritized the technical descriptors to be deployed into a training program to help each of the top ten skills to be achieved.

\subsection{Top Ten I mportant Skills (TTIS)}

Based on the highest values received for labor market survey of each skill, the most demanded top ten important skills by the private sector in State of Kuwait is shown in (table 2 ):

\begin{tabular}{|l|l|}
\hline No & \multicolumn{1}{|c|}{ Skills } \\
\hline 1 & Multi-purpose workers. \\
\hline 2 & Work with minimal supervision. \\
\hline 3 & Solve problems effectively and quickly. \\
\hline 4 & Strong work ethic. \\
\hline 5 & Willingness to work. \\
\hline 6 & Dependability/Reliability/Responsibility. \\
\hline 7 & Punctuality. \\
\hline 8 & Use of CAD/CAM. \\
\hline 9 & Ability to learn new skills and behavior. \\
\hline 10 & Inventory skills and knowledge. \\
\hline
\end{tabular}

Table 2. "Top Ten Important Skills most demanded for the private sector of labor market in Kuwait state".

\subsection{House Of Quality (HOQ) analysis (applying (QFD) on labor market priorities.)}

In the house of quality shown in (figure 1), the left horizontal column presents the customer's needs and the voice of customer (VOC) as they were identified and reduced to the top ten requirements and skills demanded for the private sector of 
the labor market. The top vertical columns represent the technical approaches to reach the requirements often called (HOWs). The middle part of the house of quality represents the relations between the VOC and the HOWs. The top triangle often called the roof of the house of quality represents the relations between the (HOWs). Also, the HOQ provides more parameters to be measured from different perspective, such as the level of difficulties, customer importance, importance rates, and relevant weight.

\subsection{Determining the Voice Of Customer (VOC)}

To begin a QFD process, the voice of the customer was identified and prioritized by the survey report and placed on the horizontal part of the HOQ shown in (figure 1).

Besterfield et al. (2003) show The equations are used to determine important calculations in quality function deployment house:

Scale-UP-Factor $=($ The Target Value $) \div($ Customer Rating $)$

Absolute weight $=($ Importance to Customer $) \times($ Scale-UP-Factor $)$

Relative weight $=\mathrm{b}_{\mathrm{j}}=\sum_{i=1}^{n} R_{i j} d_{i}$

Where

$b=$ row vector of relative weights for technical descriptors $(j=1, \ldots, m)$

di $=$ column vector of absolute weights for the customer requirements $(i=1, \ldots n)$

$\mathrm{Rij}=$ weight assigned to the relationship matrix

Equations 1, 2 and 3. Source: Besterfield, D. H., Besterfield, C., Besterfield, G. H. and Besterfield, M. (2003).

A sample of these calculations, the Inventory skills and knowledge Demand row is:

- The importance of rate for the demand gained one point from the scale of five. This skill can be obtained by deploying at least three technical 
descriptors, Managing tasks and meeting deadlines, Team activities, and inventory activities.

- The relation strength of the inventory skills and knowledge demand and the approach managing tasks and meeting deadlines is one point in a scale of five. Team activities approach and Inventory activities to deploy this demand got 5 points in a scale of five for the relation strength. The following parameters show the rating of this demand:

Customer importance $=1$ (This parameter is set by the customer)

Scale-UP-Factor $=($ Target value $\div$ Customer Comparative $)$

$$
=(2 \div 2)=1
$$

Absolute weight $=($ Customer importance $\times$ Scale-up $)$

$$
=(1 \times 1)=1
$$

\subsection{The technical descriptors to deploy the skills into a program (HOWs)}

The vertical columns of the House Of Quality (HOQ) presents the approaches to be deployed to satisfy the customer needs. Which parameter that have more an approach receives from the correlation matrix, will have to be more considered weight in the prioritization stage.

Technical descriptors parameters;

Organizational Difficulties: This parameter is to be set by the organization experts based on the organizations' abilities to deploy a technical descriptor.

- Technical competitive assessment: This parameter shows the actual and the current level of a technical descriptor of the organization.

- Target benchmark: This parameter shows the target for the organization to reach for a specific technical descriptor.

HOW columns were calculated as in equations 1 to 3 above. As a sample of these calculations, (Team Projects Technical Descriptor) parameter correlate with (Work 
with Minimal Supervision) parameter and (Willingness to Work) parameter in weak relationship weighting. The following parameters show its priorities:

Absolute weight $=((1 \times 5)+(1 \times 5))=10$

Relevant weight $=((1 \times 20)+(1 \times 13))=33$

\subsection{The roof of the House Of Quality (HOQ)}

The roof of the house of quality (HOQ) defines the relationships between the technical descriptors (HOWs) strength and how they are related to each other.

Based on the strength of the relations, priorities to deploy these approaches can be clarified. The approaches of (HOWs) can be classified as Primary and Secondary. The primary approaches are those encouraged to be used for more than one of the voice of customer's demands and they are general in nature, while the secondary approaches can be used to enrich the deployment of the skills needed to satisfy the customer needs and they are specific in nature.

The relationships between the technical descriptors (HOWs)

Measuring the relation between the approaches (HOWs) is a very important stage to prioritize the approaches to be deployed in a program. The priority would be for the approaches that have stronger relationships, first followed by the weaker ones.

\section{The technical descriptors priorities}

The house of quality technique allows prioritizing the technical descriptors based on the parameters technical difficulty, target value, absolute weight, and relative weight. The QFD team identifies technical descriptors most needed to fulfill customer requirements and need improvement. Higher absolute and relative rating identity areas these engineering efforts need to be concentrated, so:

- The first priority that found for (Practice to Be Willing in Learning- Applying New Technologies) parameter because of its highest relative weight (195 points) followed by (Understanding The Need to Learn New Skills) parameter which relative weight is 165 points. These two technical descriptors meet at the roof of the (HOQ) and form the first priority. 
- The second priority is (Simulation Activities) parameter because of its relative weight is 152 points followed by (Managing Tasks and Meeting Deadlines) parameter which relative weight is 146 points. These two technical descriptors meet at the roof of the (HOQ) and form the second priority.

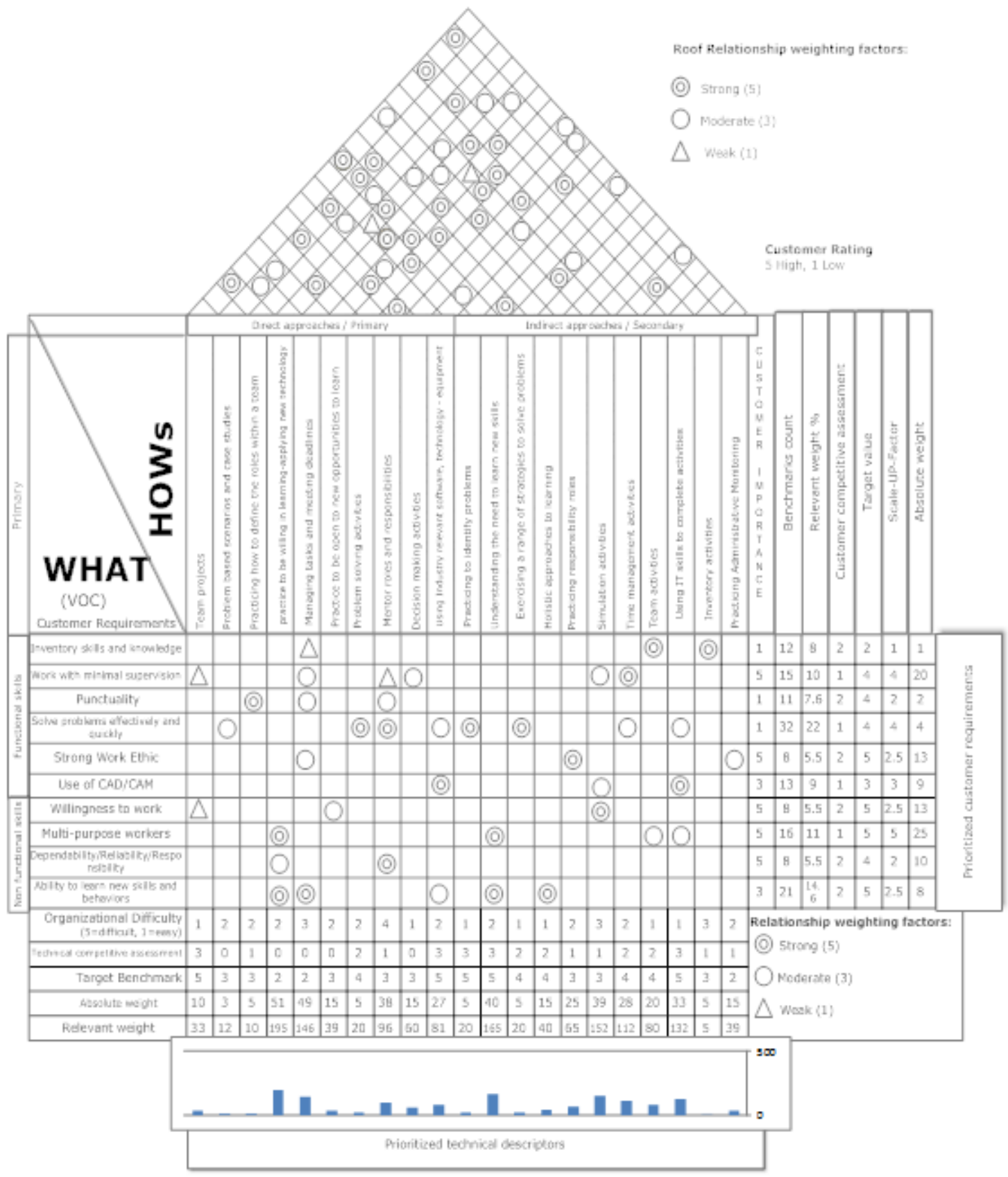

Figure1. "Applied HOQ for top important ten skills of vocational training in Kuwait". 
- The third priority is (Using IT Skills to Complete Activities) because of its relative weight is 132 points followed by (Time Management Activities) parameter which relative weight is 112 points. These two technical descriptors meet at the roof of the HOQ and form the third priority.

\subsection{Organizational difficulty}

The organizational difficulty parameter in the $\mathrm{HOQ}$ is to measure the difficulty of each technical descriptor to be deployed in the program. The level of difficulties is based on the evaluation of the QFD team with correlations for the demands in the matrix section. Setting difficulty rate helps identifying the ability to implement certain quality improvement.

\section{Deployment difficulties}

Deployment difficulties are a parameter to be set by the organizations' experts. Depending on the ability of an organization a program can be designed and targets can be set. The range of the deployment difficulties in this paper is ranked from one to five, where one is easy and five is very difficult.

- The deployment of the approach of (Team projects into the demand Inventory skills) was ranked easy, because it gets only one point in a scale of five.

- The deployment of the approach of (Problem based scenarios and case studies into the demand Solve problems effectively and quickly) was ranked need more effort because it received 2 point out of five.

- The deployment of the approach of (Practicing how to define the roles within a team to satisfy the demand Punctuality Skills) was ranked need more effort because it received two point out of five.

- The deployment of the approaches of (exercising a range of strategies to solve problems to satisfy the demand Solve problems effectively and quickly) was ranked easy because it received one point out of five.

- The deployment of the approach (practicing to identify problems to satisfy the demand Solve problems effectively and quickly) was ranked easy, because it received one point out of five. 
- The deployment of the approach of (practice to be willing in learningapplying new technology skills to satisfy the demand Dependability /Reliability /Responsibility and the demand Multi-purpose workers and the demand Ability to learn new skills and behaviors) was ranked need more effort because it received 2 points out of five.

- The deployment of the approach of (Managing tasks and meeting deadlines to satisfy the demands of Inventory skills, Work with minimal supervision, and solve problems effectively and quickly, and Punctuality, and Ability to learn new skills and behaviors) was ranked difficult because it received 3 points out of five.

- The deployment of the approach of (Practice to be open to new opportunities to learn to satisfy the demand Willingness to work) was ranked need more effort, because it received 2 points out of five.

- The deployment of the approach of (Understanding the need to learn new skills to satisfy the demands Multi-purpose workers and the demand of Ability to learn new skills and behaviors) was ranked need more effort, because it received two points in a scale of five.

- The deployment of the approach of (Problem solving activities to satisfy the demand of Solve problems effectively and quickly) was ranked need more effort, because it received two points out of five.

- The deployment of the approach of (Team activities to satisfy the demand of Teamwork Skills) was ranked easy, because it gets only one point in a scale of five.

- The deployment of the approach of (practicing responsibility roles to satisfy the demand of Strong Work Ethics) was ranked need more effort, because it received two points out of five.

- The deployment of the approach of (Mentor roles and responsibilities to satisfy the demands of Work with minimal supervision and the demand Dependability/Reliability/Responsibility and the demand Punctuality) was ranked difficult, because it received four points out of five. 
- The deployment of the approach of (Holistic approaches to learning to satisfy the demand of Ability to learn new skills and behaviors) was ranked easy, because it received one points out of five.

- The deployment of the approach of (Decision making activities to satisfy the demand of Work with minimal supervision received) was ranked easy, because it gets only one point in a scale of five.

- The deployment of the approach of (Simulation activities to satisfy the demand of Work with minimal supervision and the demand of CAD/CAM and the demand of Willingness to work) was ranked little difficult, because it received three points out of five.

- The deployment of the approach of (Time management activities to satisfy the demand of Work with minimal supervision and the demand of Solve problems effectively and quickly) was ranked need was more effort, because it received two points out of five.

- The deployment of the approach of (using IT skills to complete activities to satisfy the demand of Solve problems effectively and quickly) was ranked easy because it received one point out of five.

- The deployment of the approach of (Discussions making activities in the demand of work with minimal supervision) was ranked little difficult, because it received three points out of five.

- The deployment of the approach of (Practicing Administrative Monitoring to satisfy the demand of Strong Work Ethics) was ranked need more effort, because it received two points out of five.

\section{Conclusion}

The detailed calculations and values of QFD explain how the priorities can be obtained to deploy the most important technical descriptors in to a training program, and to evaluate the priorities of the customer demands. The priorities give the organization a clear vision of the problem and the solution in specifications and in details, which allow the organization to focus on the solution and make the right decision based on the priorities obtained. 
Finding detailed skills required for future manpower for the labor market can reduces the potential gap between vocational training outcome and employers expectations. This paper has several important contributions:

1. It suggests a useful solution to the design of an academic framework, where all the expectations of the private sector can be satisfied.

2. It presents a methodology for analyzing the voice of customer (VOC) expectations, as a clear identification of customer expectations is an important factor in customer satisfaction.

3. It opens the door for future research in the area of vocational training and education to solve ongoing problems.

\section{Further work}

Further work is to extend the study of using the QFD method in all the programs these submitted by field of Vocational Training to compare between the Vocational Training Providers that provide the most manpower for the private sector of the labor market in Kuwait. Also, a suggested further work is to apply the QFD to enhance the quality of the performance of the instructors/trainers from the student's perspective.

\section{References}

Besterfield, D. H., Besterfield, C., Besterfield, G. H., \& Besterfield, M. (2003). Total quality management. New Jersey: Prentice Hall, Inc.

Franceschini, F., \& Terzag, M., (1998). An Application of Quality Function Deployment to Industrial Training Courses. International journal of Quality \& Reliability Management, 15(7), 753-768.

doi: $10.1108 / 02656719810226924$

Gonzalez, M.E., Quesada, G., Gourdin, K., \& Hartley, M. (2008). Designing a supply chain management academic curriculum using QFD and benchmarking. USA Quality Assurance in Education, 16 (1), 36-60.

doi: $10.1108 / 09684880810848404$ 
Hamza, R. M. A. , \& Alrowaih, A. S. (2010). Enhancing Quality of Vocational Outcome to satisfy the labor market demands in Kuwait by using Quality Function Deployment Method. M. Sc. thesis In Industrial Engineering \& Management, College of Engineering, Gulf University.

Hoeckel, K., \& Field, S. (2008). Learning for Jobs OECD Reviews of Vocational Education and Training. Retrieved February 10th, 2010 from http://www. oecd.org

Maguad, B. A. (2009). Using Quality Function Deployment to evaluate government services from the customer's perspective. ASBBS Annual Conference: Las Vegas 16 (1). Retrieved from www.asbbs.org/files/2009/PDF/M/MaguadB.pdf

Manpower Government Reconstructing Program (MGRP) record, State of Kuwait. Retrieved J anuary 2nd 2010 from http://www. mgrp.org.kw/UIEN/default.aspx

Mazur, G. E. (1994). QFD for Small Business. A Shortcut through the Maza of Matrices. Transactions from the Sixth Symposium on Quality Function Deployment Novi, Michigan. Retrieved from http://www.mazur.net/works/sme_gfd.pdf

Noonan, K., Bloom, R., Aschwanden, J., Bersin, A., Chan, Y., Fisher D., Green, R. E., Lopez, D., Nuñez, J., Williams, J., \& Estep, A.(2007). Career Technical Education Framework for California Public Schools Edited by Ed O'Malley of CDE Press. Retrieved April 15th, 2010, from

http://www.cde.ca.gov/ci/ct/sf/documents/cteframework.pdf

Seyfried, E. (1998). Evaluation of Quality Aspects in Vocational Training Programs. Synthesis Report. Berlin: CEDEFOP. Retrieved from www.cedefop.europa.eu/etv/Upload/Information.../15_en_seyfried.pdf

SSDA, (2007). Draft Guidance to Sector Skills Councils on Developing, Reviewing and Promoting National Occupational Standards. Retrieved September 25th, 2010 from http://www.en.wikipedia.org/.../National_Occupational_Standard. 
Article's contents are provided on a Attribution-Non Commercial 3.0 Creative commons license. Readers are allowed to copy, distribute and communicate article's contents, provided the author's and Journal of Industrial Engineering and Management's names are included. It must not be used for commercial purposes. To see the complete license contents, please visit http://creativecommons.org/licenses/by-nc/3.0/. 